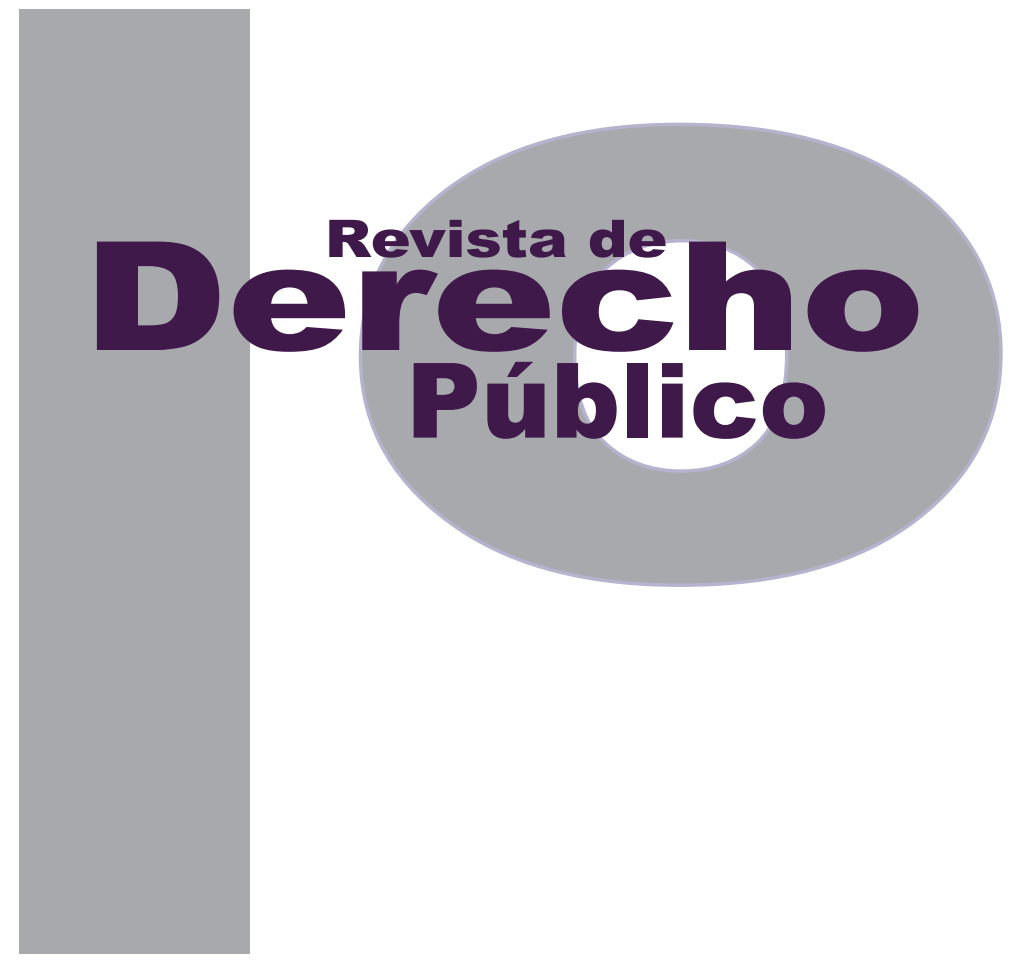

\title{
EL CRITERIO DE SOSTENIBILIDAD FISCAL: UN CUESTIONAMIENTO SOBRE LOS EFECTOS DEL ACTO LEGISLATIVO 03 DE 2011
}

\author{
JuAn CAMILO Gómez FajaRdo
}

Artículo de reflexión

DOI: http://dx.doi.org/10.15425/redepub.35.2015.12

Universidad de los Andes

Facultad de Derecho

Rev. derecho publico No.35

julio - diciembre de 2015. ISSN 1909-7778 


\title{
El criterio de sostenibilidad fiscal: un cuestionamiento sobre los efectos del Acto Legislativo 03 de 2011
}

\section{Resumen}

El Acto Legislativo 03 de 2011 introduce la sostenibilidad fiscal en la Constitución colombiana como un criterio orientador de los órganos y poderes del Estado. Desde su trámite legislativo, generó un agitado debate tanto dentro como fuera del Congreso. Dicho debate ha enfrentado a quienes afirman que el Estado social de derecho se ve vulnerado por la reforma con quienes defienden la estabilidad macroeconómica como una necesidad del Estado. Entre otras características, estas dos posiciones comparten un presupuesto: la eficacia prácticamente absoluta del acto legislativo. Este trabajo, por medio de una revisión de varios documentos relevantes, pretende encontrar un punto alternativo entre esas dos posiciones y aproximarse críticamente a los efectos de la reforma, para cuestionar su eficacia. Se sostiene que el acto legislativo no es realmente eficaz por cuanto no ha producido un cambio de paradigma en la manera como los poderes del Estado desarrollan sus funciones y toman decisiones.

Palabras clave: sostenibilidad fiscal, eficacia, reforma constitucional, Estado social de derecho, derechos sociales, estabilidad macroeconómica, poderes del Estado.

\section{The Fiscal Sustainability Criterion: Questioning the Effects of Legislative Act 03 of 2011}

\begin{abstract}
Legislative Act 03 of 2011 introduces fiscal sustainability to the Colombian Constitution as a guiding criterion for state branches and authorities. Since its legislative process, it generated a heated debate both inside and outside Congress. This debate pits those who claim that the social rule of law is breached by the reform against those who stand up for macroeconomic stability as a necessity of the state. Among other features, these two positions share an implicit assumption: the almost total efficacy of the amendment. This piece, through a review of several relevant documents, aims to find an alternative point between these two positions and take a critical approach to the effects of the reform, in order to question its efficacy. The author argues that the legislative act is not truly effective, given the fact that it has not produced a paradigm shift in the way the branches of government perform their duties and make decisions.
\end{abstract}

Keywords: fiscal sustainability, efficacy, constitutional amendment, social rule of law, social rights, macroeconomic stability, branches of government.

\section{O critério de sustentabilidade fiscal: um questionamento sobre os efeitos do Ato Legislativo 03 de 2011}

\section{Resumo}

O Ato Legislativo 03 de 2011 introduz a sustentabilidade fiscal na Constituição colombiana como um critério orientador dos órgãos e poderes do Estado. Desde seu trâmite legislativo, gerou um agitado debate tanto dentro quanto fora do Congresso. Dito debate tem enfrentado aqueles que afirmam que o Estado social de direito se vê vulnerado pela reforma, com aqueles que defendem a estabilidade macroeconômica como uma necessidade do Estado. Entre outras características, estas duas posições compartilham um pressuposto: a eficácia praticamente absoluta do ato legislativo. Este trabalho, por meio de uma revisão de vários documentos relevantes, pretende encontrar um ponto alternativo entre essas duas posições e aproximar-se criticamente dos efeitos da reforma, para questionar sua eficácia. Sustenta-se que o ato legislativo não é realmente eficaz enquanto não tiver produzido uma mudança de paradigma na maneira como os poderes do Estado desenvolvem suas funções e tomam decisões.

Palavras-chave: sustentabilidade fiscal, eficácia, reforma constitucional, Estado social de direito, direitos sociais, estabilidade macroeconômica, poderes do Estado. 


\title{
El criterio de sostenibilidad fiscal: un cuestionamiento sobre los efectos del Acto Legislativo 03 de 2011*
}

\author{
Juan Camilo Gómez Fajardo ${ }^{* *}$
}

\section{SUMARIO}

Introducción - I. LA REFORMA CONSTITUCIONAL Y EL ESTADO DEL DEBATE - A. La sostenibilidad fiscal: un debate no coyuntural - B. El Acto Legislativo 03 de 2011: contenido de la reforma - C. Sobre el debate alrededor de la reforma - 1. El trámite legislativo de la reforma - 1.1. El proyecto presentado por el Gobierno y su exposición de motivos - 1.2. El proyecto en el Congreso: argumentos centrales - 1.3. Principales modificaciones realizadas al proyecto del Gobierno - 2. La discusión fuera del Congreso - D. Control de constitucionalidad de la reforma: jurisprudencia de la Corte Constitucional - II. EL CRITERIO DE SOSTENIBILIDAD FISCAL: ¿REALMENTE EFICAZ? - A. La sostenibilidad fiscal en el Poder Legislativo: discusiones antiguas e intentos de desarrollo del Acto Legislativo 03 de 2011 - 1. Proyectos relacionados con gasto público social - 2. Proyectos directamente referidos al Acto Legislativo 03 de 2011 - 3. Conceptos del Gobierno sobre proyectos de ley - B. La sostenibilidad fiscal en el Poder Ejecutivo: una preocupación de vieja data - C. La sostenibilidad fiscal en el Poder Judicial: reiteración de jurisprudencia - 1. Sentencias de constitucionalidad en las que se reiteran las consideraciones de la C-288 de 2012 - 2. Sentencias de tutela en las que se rechazan argumentos de sostenibilidad fiscal - 3. La sentencia SU-1073 de 2012 y la polémica alrededor suyo - 4. Aplicación del incidente de impacto fiscal - III. CONCLUSIONES - Referencias.

Cómo citar este artículo: Gómez Fajardo, J. C. (Diciembre, 2015). El criterio de sostenibilidad fiscal: un cuestionamiento sobre los efectos del Acto Legislativo 03 de 2011. Revista de Derecho Público, 35. Universidad de los Andes (Colombia).

** Abogado de la Universidad de los Andes con opción en Economía de la misma institución. En la actualidad se desempeña como asociado de la firma Brigard \& Urrutia Abogados. Correos: juancgomezfajardo@gmail.com o jc.gomez377@uniandes.edu.co

El autor agradece especialmente al profesor Eduardo Cifuentes Muñoz por sus valiosos comentarios durante la elaboración de este texto, así como a Rodolfo Arango, Marcela Eslava, Mónica Pachón, Roberto Steiner y Miguel Urrutia por dedicar una parte de su tiempo a conversar sobre sus perspectivas alrededor del tema de este artículo. 
Introducción

La reforma constitucional que introdujo el criterio de sostenibilidad fiscal se encuentra contenida en el Acto Legislativo 03 de 2011, promulgado el 1 de julio de ese año. Desde el momento en que el proyecto fue radicado en el Congreso, surgió una agitada discusión que tuvo lugar tanto dentro como fuera del debate legislativo, en ámbitos como la academia, la justicia y los medios de comunicación. Cuatro días después de la fecha mencionada, fue promulgada la Ley 1473 de 2011, "por medio de la cual se establece una regla fiscal". Esta figura se suma a la enmienda constitucional, para complementar el paquete de medidas mediante el cual el Gobierno pretendía promover la disciplina en el manejo de las finanzas públicas. Aunque esta ley hizo parte de la polémica, el tema de la sostenibilidad fiscal fue el foco del debate. La discusión revivió recientemente, como consecuencia del trámite y de la promulgación de la Ley 1695 de 2013, que reglamenta el incidente de impacto fiscal, mecanismo previsto en la reforma constitucional de 2011.

Esta discusión se enmarca dentro de una más amplia que, se puede decir, cobra vigencia en Colombia con la promulgación de la Constitución de 1991 y adquiere más fuerza con las múltiples decisiones de la Corte Constitucional, que tienen contenido económico o que, por lo menos, implican gastos para el Estado. ${ }^{1}$ Este debate no es otro que aquel cuyas partes han sido reducidas por la literatura a abogados y economistas o,

1 Véase Kalmanovitz (1999). en su defecto, a las disciplinas del derecho y la economía (Uprimny, 2006; Uprimny y Rodríguez, 2010). Inclusive, durante el trámite del acto legislativo en comento, el entonces ministro de Hacienda y Crédito Público, Juan Carlos Echeverry, llegó a referirse a quienes intervienen en dicho debate en estos mismos términos:

Con la Corte Constitucional hemos mantenido una muy amable discusión, ya lleva más o menos quince años (...) ¿a quiénes me refiero? $A$ Ios economistas y a los abogados, ya hay una discusión de la que hemos aprendido muchísimo en el país en los últimos [sic] pues ya veinte años casi, en la cual los economistas primero resentíamos fallos muy costosos de la Corte (Gaceta del Congreso 960 de 2010, pág. 35. Cursivas añadidas).

Varios expertos, como Steiner (2011), clasifican a las partes de esa manera, incluso específicamente en referencia a la discusión sobre la sostenibilidad fiscal.

No obstante, habiendo examinado los argumentos de cada una de las posiciones, en este trabajo se hace referencia a la controversia de forma diferente, con el propósito de incluir otros matices: en un extremo, se encuentran quienes defienden el Estado social de derecho, y los derechos sociales y la acción de tutela como dos de sus pilares más importantes; en el otro, aparecen quienes están a favor de la estabilidad macroeconómica y de la disciplina en el manejo de la política estatal de gasto.

Tras analizar el debate mencionado, en este texto se señala que los argumentos de estas dos 
posiciones tienen, al menos, dos características en común. Por un lado, tanto las posturas como sus argumentos son absolutamente radicales; cada una se encuentra en un extremo del debate, totalmente alejada de la otra y, en términos generales, no existen puntos medios en la discusión. Por el otro, ambas tienen un presupuesto en común: asumen que la reforma cumple y cumplirá a cabalidad con todos los objetivos que, para bien o para mal -según el extremo de la discusión en el que se esté-, se encuentran detrás de ella; y que, en consecuencia, producirá todos los efectos, plausibles o nefastos, que se espera que provoque. En otras palabras, una y otra presuponen como un hecho la eficacia prácticamente total de la reforma y parten de que, en cualquier caso, generará un cambio de paradigma en la relación entre la estabilidad macroeconómica y los postulados del Estado social de derecho.

Este texto pretende, entonces, dar nuevas luces y abrir nuevas perspectivas con respecto al segundo punto en común, detectado en los argumentos de las posiciones descritas anteriormente: la asunción de la eficacia del criterio de sostenibilidad fiscal. Con este objetivo, se hace un estudio centrado en el acto legislativo mencionado y en el estado del debate suscitado por la reforma, con el fin de cuestionar la eficacia de la enmienda constitucional. De esa manera, en el marco de una discusión caracterizada, como ya se dijo, por una marcada polarización, se busca encontrar, con respecto a los efectos reales del acto legislativo, un punto alternativo entre las dos posiciones explicadas. En este trabajo se sostiene que, hasta este momento, el criterio de sostenibilidad fiscal no ha sido verdaderamente eficaz, por cuanto no ha ocasionado un cambio de paradigma ni en el desarrollo de las funciones ni en la toma de decisiones de los poderes y órganos del Estado.

El escrito se divide en dos partes fundamentales. La primera estudia el acto legislativo y aborda, desde una perspectiva descriptiva, los argumentos del debate que este ha producido tanto dentro como fuera del Congreso. Así, se evidencian las dos características que, según se afirmó anteriormente, tienen en común las dos posturas. Además, para aportar elementos al estado del debate, se estudia el único pronunciamiento de fondo de la Corte Constitucional sobre la materia: la sentencia C-288 de 2012 (L. E. Vargas). La metodología empleada en este acápite del trabajo consistió en una revisión de diferentes documentos que se citan para construir el marco teórico (normativa, Gaceta del Congreso, doctrina, artículos académicos y de prensa, y jurisprudencia). La segunda parte del trabajo se centra en la eficacia de la reforma. Con base en una revisión documental, se presenta una serie de argumentos para sustentar la tesis planteada con respecto a este punto.

\section{LA REFORMA CONSTITUCIONAL Y EL ESTADO DEL DEBATE}

En las páginas siguientes se explicarán, en primer lugar, los antecedentes y el contenido de la reforma. Luego, se hará una síntesis de su trámite legislativo, lo cual nos llevará a estudiar 1) el proyecto presentado en un principio por el 
gobierno de Álvaro Uribe y su exposición de motivos, 2) los principales argumentos que se esgrimieron durante las discusiones en el Congreso, y 3) las más importantes modificaciones que sufrió durante el trámite. Acto seguido, se hará referencia a algunos de los argumentos que han surgido en el debate generado por fuera del Congreso. Finalmente, se estudiará la sentencia C-288 de 2012 (L. E. Vargas).

\section{A. La sostenibilidad fiscal: un debate no coyuntural}

¿Qué es la sostenibilidad fiscal? Una de las particularidades del acto legislativo en estudio y, en general, del debate surgido alrededor suyo, es que no se observa una definición concreta del término. De hecho, como la Corte Constitucional anota, el concepto, "según la doctrina económica, no es unívoco" (C-288/2012, L. E. Vargas). Además, en economía, el tema ha sido objeto de discusión desde hace muchos años (Afonso, 2004). Así, en Colombia, la preocupación del Gobierno por la sostenibilidad fiscal es prácticamente inherente a sus funciones, pues según la Constitución, este es el ente encargado de manejar las finanzas públicas y la política de gasto. Por lo tanto, este tema no aparece en la agenda económica y política del país con la promulgación del acto legislativo; es un debate estructural que, como se verá en las definiciones que se citan a continuación, existe desde antes de 2011.

En la literatura económica, Alonso, Olivera y Fainboim (1998) afirman que "el concepto de ‘sostenibilidad fiscal' alude (...) a las restriccio- nes de largo plazo que enfrenta la política fiscal, asociadas básicamente con la dinámica de la relación entre la deuda pública y el PIB" (pág. 29). Los mismos autores señalan que un análisis de sostenibilidad apunta a:

Determinar si existe la posibilidad de financiar los aumentos de carácter permanente en el gasto público mediante los ingresos esperados por el gobierno en el mediano y largo plazo, o si se requiere de nuevos incrementos de impuestos $y / 0$ reducciones en el gasto, para evitar déficits fiscales persistentes y un crecimiento sin límites de la deuda pública (Alonso et al., 1998, pág. 29).

Los análisis de este tipo le permiten al Gobierno establecer si es factible "que el flujo presente y futuro de sus ingresos sea capaz de cubrir sus obligaciones presentes y futuras a fin de evitar que se vea enfrentado a una quiebra, liquidación o crisis" (Ministerio de Hacienda y Crédito Público, 2002, pág. 41). La Corte Constitucional indica que el criterio "está dirigido a disciplinar las finanzas públicas, de manera tal que la proyección hacia su desarrollo futuro reduzca el déficit fiscal" (C-288/2012, L. E. Vargas). Para resumir, entonces, la sostenibilidad fiscal hace referencia, en términos generales, a una relación de equilibrio, en el largo plazo, entre los ingresos y los gastos del Estado, que garantice que los primeros sean suficientes para cubrir los segundos. 


\section{B. El Acto Legislativo 03 de 2011: contenido de la reforma}

El acto legislativo en comento, tal y como fue promulgado, modifica los artículos 334, 339 y 346 de la Constitución Política (CP), que hacen parte de la llamada Constitución económica ${ }^{2}$ y que se encuentran dentro del título XII de la Carta - “Del régimen económico y de la hacienda pública"-. Los artículos 339 y 346 regulan, respectivamente, el Plan Nacional de Desarrollo, y el presupuesto de rentas y ley de apropiaciones. Estos dos artículos sufrieron modificaciones menores: en los dos casos, el acto legislativo establece que estos instrumentos se deben elaborar y aprobar dentro de un marco de sosteni-

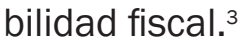

2

La Constitución económica es definida como "las normas constitucionales que ordenan la vida económica de la sociedad y establecen el marco jurídico esencial para la estructuración y funcionamiento de la actividad material productiva" (CConst., C-265/1994, A. Martínez).

3 Esta es la versión del artículo 339 posterior a la reforma (en cursivas el aparte introducido): “ARTículo 339. Habrá un Plan Nacional de Desarrollo conformado por una parte general y un plan de inversiones de las entidades públicas del orden nacional. En la parte general se señalarán los propósitos y objetivos nacionales de largo plazo, las metas y prioridades de la acción estatal a mediano plazo y las estrategias y orientaciones generales de la política económica, social y ambiental que serán adoptadas por el Gobierno. El plan de inversiones públicas contendrá los presupuestos plurianuales de los principales programas y proyectos de inversión pública nacional y la especificación de los recursos financieros requeridos para su ejecución, dentro de un marco que garantice la sostenibilidad fiscal.

Las entidades territoriales elaborarán y adoptarán de manera concertada entre ellas y el gobierno nacional, planes de desarrollo, con el objeto de asegurar el uso eficiente de sus recursos y el desempeño adecuado de las funciones que les hayan sido asignadas por la Constitución y la ley. Los planes de las entidades territoriales estarán conformados por una parte estratégica y un plan de inversiones de mediano y corto plazo" (CP, art. 339).

En el caso del artículo 346, se modificó la redacción del inciso $1^{\circ}$, pero en términos prácticos, simplemente se adicionó el aparte que aparece en cursivas: "ARTicuLo 346. El Gobierno formulará anualmente el presupuesto de rentas y ley de apropiaciones, que será presentado al Congreso dentro de los primeros diez días de cada legislatura. EI
Sin duda, es en las modificaciones introducidas al artículo 334 donde radica el núcleo de la reforma. Este artículo establece que la dirección general de la economía le corresponde al Estado, por lo que este debe intervenir en determinadas materias económicas. ${ }^{4}$ El acto legislativo introduce algunos apartes al artículo y determina que la intervención del Estado en la economía se debe realizar también en un marco de sostenibilidad fiscal, que "deberá fungir como instrumento para alcanzar de manera progresiva los objetivos del Estado Social de Derecho" (cP, art. 334). Igualmente, la norma en comento dispone que "en cualquier caso el gasto público social será prioritario" (CP, art. 334). Al inciso $2^{\circ}$, además, se le realizaron un par de adiciones alusivas a la progresividad en la garantía de acceso a los bienes y servicios básicos por parte de la población, ${ }^{5}$ en especial la de menores ingresos.

presupuesto de rentas y ley de apropiaciones deberá elaborarse, presentarse y aprobarse dentro de un marco de sostenibilidad fiscal y corresponder al Plan Nacional de Desarrollo.

En la Ley de Apropiaciones no podrá incluirse partida alguna que no corresponda a un crédito judicialmente reconocido, o a un gasto decretado conforme a ley anterior, o a uno propuesto por el Gobierno para atender debidamente el funcionamiento de las ramas del poder público, o al servicio de la deuda, o destinado a dar cumplimiento al Plan Nacional de Desarrollo.

Las comisiones de asuntos económicos de las dos cámaras deliberarán en forma conjunta para dar primer debate al proyecto de Presupuesto de Rentas y Ley de Apropiaciones" (cP, art. 346).

4 Estas son las materias que enlista el artículo 334: la explotación de los recursos naturales, el uso del suelo, la producción, distribución, utilización y consumo de los bienes, y los servicios públicos y privados.

5 Texto del inciso $2^{\circ}$ del artículo 334 posterior a la reforma (las adiciones se resaltan en cursivas): "El Estado, de manera especial, intervendrá para dar pleno empleo a los recursos humanos y asegurar, de manera progresiva, que todas las personas, en particular las de menores ingresos, tengan acceso efectivo al conjunto de los bienes y servicios básicos. También para promover la productividad y competitividad y el desarrollo armónico de las regiones" (cP, art. 334). 
Adicionalmente, se introdujeron dos incisos: uno referente a la incidencia de la sostenibilidad fiscal como criterio orientador de las ramas y órganos del poder público, ${ }^{6}$ y otro que enuncia la existencia del mecanismo procesal en el que se materializa la sostenibilidad fiscal. Este es uno de los puntos más polémicos de la reforma: el incidente de impacto fiscal. ${ }^{7}$ Finalmente, en atención a los sectores críticos de la reforma, se agregó un parágrafo al artículo 334, según el cual, al interpretar dicho artículo, ninguna autoridad puede invocar la sostenibilidad fiscal "para menoscabar los derechos fundamentales, restringir su alcance o negar su protección efectiva" (cP, art. 334).

\section{Sobre el debate alrededor de la reforma}

Las dos posiciones explicadas anteriormente una a favor del Estado social de derecho, los derechos sociales y la acción de tutela, y la otra de la estabilidad macroeconómica- se observan tanto en las discusiones de las que fue objeto el proyecto de acto legislativo durante su trámite en el Congreso como en el fuerte debate que la reforma ha suscitado fuera de este. De igual

6 Texto del inciso introducido: "La sostenibilidad fiscal debe orientar a las Ramas y Órganos del Poder Público, dentro de sus competencias, en un marco de colaboración armónica" (CP, art. 334).

7 El inciso introducido es el siguiente: "El Procurador General de la Nación o uno de los Ministros del Gobierno, una vez proferida la sentencia por cualquiera de las máximas corporaciones judiciales, podrán solicitar la apertura de un Incidente de Impacto Fiscal, cuyo trámite será obligatorio. Se oirán las explicaciones de los proponentes sobre las consecuencias de la sentencia en las finanzas públicas, así como el plan concreto para su cumplimiento y se decidirá si procede modular, modificar o diferir los efectos de la misma, con el objeto de evitar alteraciones serias de la sostenibilidad fiscal. En ningún caso se afectará el núcleo esencial de los derechos fundamentales" (CP, art. 334). manera, tanto dentro como fuera del Congreso, los argumentos de las dos posturas cumplen con las dos características identificadas: 1) una extrema polarización y 2) la asunción y certeza sobre la eficacia del acto legislativo, para bien o para mal. En los siguientes párrafos se realizará una síntesis del trámite legislativo del proyecto y se explicarán los principales argumentos de quienes defienden la reforma y de quienes la atacan, para evidenciar la existencia de esas dos características.

\section{El trámite legislativo de la reforma}

Un análisis del trámite del Acto Legislativo 03 de 2011 en el Congreso de la República nos Ileva necesariamente a referirnos, por un lado, al nacimiento del proyecto en el gobierno de Álvaro Uribe, así como a los argumentos con los que se defendió en un principio y, por otro, al trámite legislativo como tal, que se inició en la Comisión Primera de la Cámara de Representantes.

\subsection{El proyecto presentado por el Gobierno y su exposición de motivos}

El proyecto de acto legislativo fue presentado al final del gobierno Uribe, pero contó desde el principio con el apoyo y la participación de los futuros miembros del de Juan Manuel Santos -en específico de Juan Carlos Echeverry, su primer ministro de Hacienda y Crédito Público-. El proyecto fue radicado en la Cámara de Representantes el 20 de julio de 2010 por los ministros de Hacienda saliente y entrante -Óscar Iván Zuluaga y Juan Carlos Echeverry, respectivamente-(Lewin, 2011). Al momento de 
su presentación, el proyecto llevaba el siguiente título: "por el cual se establece el derecho a la sostenibilidad fiscal para alcanzar los fines del estado social de derecho" (Gaceta del Congreso 451 de 2010, pág. 13. Cursivas añadidas). Solo con leer este encabezado, surge un primer punto relevante, que será analizado a profundidad más adelante: en su versión original, el proyecto buscaba la introducción de un derecho colectivo a la sostenibilidad fiscal (CConst., C-288/2012, L. E. Vargas; González, J. I., 2011). Igualmente, introducía dos incisos al artículo 334 de la Constitución, que fueron rápidamente descartados en los primeros debates:

La sostenibilidad fiscal es indispensable para alcanzar los fines del Estado Social de Derecho. Por lo tanto es un derecho de todos y es deber de todas las ramas y órganos del poder público colaborar armónicamente, dentro de sus competencias, para hacerla efectiva.

El Congreso de la República, al determinar el alcance concreto de los derechos sociales y económicos consagrados en esta Constitución, deberá hacerlo en tal forma que asegure la sostenibilidad fiscal con el fin de darles, en conjunto, continuidad y progresividad (Gaceta del Congreso 451 de 2010, pág. 13. Cursivas añadidas).

Estos dos incisos hacían alusión a dos puntos especialmente polémicos de la enmienda constitucional que salieron de su redacción durante el trámite en el Congreso. Por una parte, como ya se anotó, el Gobierno pretendía darle el rango de derecho a la sostenibilidad fiscal. Por la otra, forzaba al Congreso a delimitar los dere- chos sociales y económicos de acuerdo con los parámetros de sostenibilidad. A pesar de que este elemento no se mantuvo en la versión promulgada, siguen lloviendo críticas que auguran el fin de la protección judicial de los derechos sociales en Colombia.

Ahora bien, al estudiar la exposición de motivos con la que el proyecto fue radicado en la Cámara de Representantes, se observa una tercera característica en común que tienen los argumentos de las dos posiciones del debate: ${ }^{8}$ las dos posturas construyen buena parte de su argumentación a partir de la defensa del Estado social de derecho e incluso de la efectividad de los derechos sociales. Así, desde la misma exposición de motivos se observa que el Gobierno afirma:

La sostenibilidad fiscal es importante para el progreso económico y social de un país en la medida en que el sector público busca que, ante una determinada y limitada capacidad para recaudar ingresos y para acceder a recursos de financiamiento, la política de gasto pueda mantenerse o sostenerse en el tiempo, de manera que en el mediano y en el largo plazo se logren importantes objetivos públicos, como la reducción de la pobreza y la desigualdad y la equidad intergeneracional, y un crecimiento económico estable (Gaceta del Congreso 451 de 2010, pág. 14).9

Ya anteriormente se hizo referencia a dos de estas características al hablar de dos supuestos de los que parte este trabajo: 1) los argumentos de las dos posturas son totalmente radicales, por lo que no existen realmente puntos medios en la discusión, tal y como se ha dado; 2) las dos posturas y sus argumentos asumen la eficacia de la reforma.

9 Estos argumentos se reiteran en un documento publicado por el Ministerio de Hacienda, ya durante el gobierno Santos, y entre cuyos 
En este orden de ideas, se establece claramente que la sostenibilidad fiscal es un "instrumento de protección de los derechos sociales de los colombianos, y como tal, de la realización de los fines del Estado Social de Derecho" (Gaceta del Congreso 451 de 2010, pág. 17. Cursivas añadidas).

De los argumentos de la exposición de motivos cabe resaltar también uno que llama la atención y que se reitera durante los debates en el Congreso. El Gobierno (tanto el de Uribe como el de Santos) justifica la importancia de la reforma al afirmar que la misma Corte Constitucional ha reconocido su necesidad. Durante el trámite legislativo, como ya se verá, el Gobierno llega a referirse de manera más específica a la relación entre la Corte Constitucional y la reforma.

\subsection{El proyecto en el Congreso: argumentos centrales}

Al examinar los números de la Gaceta del Congreso en los que se registraron las actas de los debates durante los que se discutió el proyecto, se observa que las posturas y los argumentos presentados en estos cumplen con los supuestos a los que ya se ha hecho referencia. Desde el inicio del trámite, las ponencias favorables fueron las mayoritarias, pues las bancadas de los partidos pertenecientes en ese momento a la coalición de la Unidad Nacional (Partido de la U, Partido Conservador, Partido Liberal y Cambio Radical) naturalmente apoyaron el proyecto. Esto lleva a que en el Congreso hayan sido más

autores aparece, entre otros, el ministro de Hacienda del gobierno Uribe, Óscar Iván Zuluaga (Zuluaga, Palacios, Alonso y Quintero, 2011). comunes los argumentos a favor de la sostenibilidad fiscal. Como se verá, no ocurre lo mismo fuera del ámbito legislativo.

En las intervenciones de los congresistas de la Unidad Nacional se detecta un punto en común: insisten en que son defensores del Estado social de derecho y, por lo tanto, resaltan que la sostenibilidad fiscal es un instrumento para cumplir con este postulado y con la efectividad de los derechos sociales. ${ }^{10}$ También se evidencia, en algunas de estas participaciones, que la reforma está dirigida a mitigar la intervención judicial en la economía, en especial la de la Corte Constitucional. Así, en algunos casos las palabras de los congresistas se refieren a la "dictadura de los jueces" como causa de la inviabilidad de las finanzas del Estado. ${ }^{11}$ Igualmente, para sus-

10 Así, por ejemplo, en el primer debate, el representante Jaime Buenahora, del Partido de la $U$ y coordinador de la ponencia favorable, afirma: "Y quiero compartirles apreciados colegas que soy el mayor defensor del Estado Social de Derecho, siempre lo he hecho en escritos, en múltiples intervenciones y que este es un tema profundamente delicado porque nos coloca en una dialéctica nada fácil entre la filosofía del Estado de Derecho y la sociología del Estado de Derecho" (Gaceta del Congreso 960 de 2010, pág. 5).

El representante Miguel Gómez, también del Partido de la U, señala en ese mismo debate: "Entonces tranquilos los que estén preocupados por el gasto social, tranquilos, sin viabilidad fiscal no hay redistribución del ingreso, si este país no es viable fiscalmente no puede redistribuir el ingreso, si este país no es viable fiscalmente no puede haber programas de equidad, si este país no es viable fiscalmente no va a haber derechos sociales, si este país no es viable fiscalmente no va a haber empleo, ni prosperidad. Entonces no se preocupen, la sostenibilidad fiscal lo único que puede es, contribuir a que nuestros sueños algún día se vuelvan realidad" (Gaceta del Congreso 960 de 2010, pág. 34).

11 Por ejemplo, el representante Didier Burgos expresó: "Recordemos que esta iniciativa partió del gobierno pasado, del Ministro de Hacienda Óscar Iván Zuluaga, respondiendo a una inquietud y a una necesidad que tenía el Estado, que tenía el gobierno, de ponerle una cortapisa a la dictadura de los jueces.

Está bien que los colombianos tengamos el derecho a la vivienda, el derecho a la salud, el derecho a la vida, a todos los derechos fundamentales, pero es que por la vía del amparo judicial, por la vía de la dictadura de los jueces, estábamos llegando a la inviabilidad fiscal 
tentar esta afrenta contra la rama judicial, los congresistas prorreforma acuden a argumentos basados en el principio de división de poderes, específicamente en contra del ejercicio de facultades propias del Congreso por parte de la Corte Constitucional. ${ }^{12}$

Por su parte, el Gobierno apoya también este tipo de argumentos y llama a los congresistas a pensar en las generaciones futuras y en la necesidad de un manejo disciplinado y cuidadoso del gasto para garantizar un futuro prometedor para estas. Además, en el primer debate, el ministro Echeverry afirma que los magistrados de la Corte Constitucional le habían manifestado al entonces ministro Zuluaga, que el alto tribunal no podía incorporar un análisis fiscal en sus fallos porque no había una disposición constitucional que se lo permitiera. Por lo tanto, Echeverry asevera que el proyecto había sido presentado por sugerencia de los mismos magistrados de la Corte. ${ }^{13}$

del Estado colombiano" (Gaceta del Congreso 948 de 2010, pág. 38. Cursivas añadidas).

12 Las siguientes son palabras de la congresista Adriana Franco, del Partido Liberal: "Pero también tenemos que buscar equilibrar la balanza y yo creo que nosotros los legisladores hemos perdido un espacio importante en el país y hemos permitido que de alguna manera la Corte venga pronunciándose reiteradamente sobre tareas que teníamos que asumir nosotros y fijar parámetros claros" (Gaceta del Congreso 960 de 2010, pág. 18).

13 Palabras textuales de Echeverry, tal y como aparecen consignadas en la Gaceta del Congreso 960 de 2010: "La Corte Constitucional, le dijo al Ministro [Zuluaga], es que nosotros hacemos análisis formal de la Constitución, la Constitución defiende el derecho a la vida, al buen nombre, a la salud, a las pensiones, a la vivienda, pero la Constitución le dijo a la Corte, no tiene ningún tema fiscal.

De manera que nosotros como ciudadanos entendemos que el tema fiscal es importante, pero como analistas y como garantes de la Constitución, pues ahí no hay nada fiscal, si usted quiere que la Corte en uno de sus considerandos, no en el más importante, ni en el que reemplaza a los demás, sino que la Corte tenga en cuenta que fiscalmente el país debe ser viable, eso debe estar dentro de la
Ahora bien, los argumentos en contra de la reforma, que fueron esgrimidos sobre todo por congresistas del Partido Verde y del Polo Democrático, llamaban la atención sobre el hecho de que la reforma atentaba contra el Estado social de derecho y los derechos sociales. ${ }^{14}$ Alfonso Prada, representante del Partido Verde, quien presentó ponencia negativa desde el primer debate y fue uno de los más fuertes y contundentes opositores del proyecto, sostuvo siempre que la reforma implicaba, por esa razón, una sustitución de la Constitución (véanse, entre otras, la Gaceta del Congreso 960 de 2010 y 719 de 2011). Además, Prada identificaba en el proyecto una tensión entre el Estado social de derecho y uno, en sus palabras, economicista. ${ }^{15}$

\subsection{Principales modificaciones realizadas al proyecto del Gobierno}

Al comparar la versión del proyecto radicada por

el Gobierno con la versión que fue finalmente

Constitución para que en nuestro análisis formal eso sea contemplado, mientras eso no sea así no lo podemos contemplar.

Fue entonces una sugerencia de la Corte Constitucional lo que motivó a Óscar Iván Zuluaga" (pág. 36).

14 La siguiente intervención del representante Iván Cepeda resume, a pesar de su corte radical, la opinión que la oposición, en términos generales, tenía del proyecto: "Esta es una catástrofe para los derechos sociales, para los más elementales derechos fundamentales de la población, no es un derecho fundamental ni un principio rector de una estabilidad económica, no es ni siquiera en su versión más moderada un paso adelante en el desarrollo del país, es ni más ni menos que la lapidación del Estado de Derecho en su forma social y el surgimiento de un Estado autocrático en materia de libertades y derecho social" (Gaceta del Congreso 948 de 2010, pág. 41).

15 Estas son las palabras del representante Prada: "desde el punto de vista teórico se pone como debate de fondo, una concepción normativa de principios con un enfoque de derechos de Estado Constitucional y Social de Derecho por un lado, enfrentado a un enfoque de Estado economicista, utilitarista y pragmático en el que se subordina los derechos y sus garantías a la consecución de unos bienes económicos" (Gaceta del Congreso 960 de 2010, pág. 12). 
promulgada, se constatan las múltiples modificaciones realizadas a la primera. Cabe resaltar dos: 1) se abandonó la iniciativa de un derecho a la sostenibilidad fiscal y, tal y como el Congreso aprobó el acto legislativo, se prefirió introducir un criterio de sostenibilidad fiscal; 2) se introdujo el incidente de impacto fiscal, que no se preveía en el proyecto original. A continuación, se profundizará en estas dos modificaciones.

En primer lugar, se abandonó rápidamente la iniciativa de un derecho a la sostenibilidad fiscal. En el segundo debate, se pasó al concepto de principio, pues en palabras del representante Jaime Buenahora, defensor del proyecto, "no es fácil encajar el concepto de sostenibilidad fiscal como derecho, ni en tratándose de derechos fundamentales ni de derechos sociales y económicos, ni tampoco de derechos colectivos, y menos suponer que es un deber del ciudadano" (Gaceta del Congreso 948 de 2010, pág. 28).

Sin embargo, aún el concepto de principio resultaba polémico, pues los opositores al proyecto afirmaban que, en el momento en que un juez constitucional aplicara el método interpretativo de la ponderación para resolver eventuales colisiones entre la sostenibilidad fiscal y derechos constitucionales (fundamentales, sociales, económicos, colectivos o de cualquier tipo), no habría diferencia alguna entre enfrentarlos a un principio o a un derecho. En los dos casos iba a tener el mismo peso y, por lo tanto, iba a significar el mismo peligro para los derechos. ${ }^{16}$

16 Este punto llevó a que incluso el Partido Liberal, integrante de la Unidad Nacional, dudara acerca de la conveniencia de la reforma y llegara al punto de declararse en oposición, temeroso de que el
Por esa razón, el Partido Liberal logró que se abandonara el concepto de principio y presentó, en el séptimo debate, una proposición para que se redujera la sostenibilidad fiscal a un criterio (Gaceta del Congreso 491 de 2011). La proposición prosperó y el acto legislativo que el Congreso aprobó habla simplemente de un criterio orientador (Gaceta del Congreso n. ${ }^{\text {s }} 487$ y 719 de 2011). Sin embargo, el título del acto legislativo, tal y como fue sancionado por el presidente y publicado en el Diario Oficial n. ${ }^{\circ} 48.117$, reza: "por el cual se establece el principio de sostenibilidad fiscal". La razón de esta particularidad no se conoce realmente ("Título del acto legislativo", 2011). En todo caso, la Corte Constitucional se ha pronunciado sobre el tema y ha determinado que definitivamente se trata de un criterio orientador y en ningún caso de un principio constitucional (C-288/2012, L. E. Vargas). ${ }^{17}$

En segundo lugar, fue también durante el séptimo debate, por iniciativa del Partido Liberal, que se introdujo la figura del incidente de impacto fiscal. Es en ese momento que se adiciona el cuarto inciso del artículo 334, que establece, tal y como fue promulgado: "el Procurador General de la Nación o uno de los Ministros del Gobierno, una vez proferida la sentencia por cualquiera de las máximas corporaciones judiciales, podrán solicitar la apertura de un Incidente de Impacto Fiscal, cuyo trámite será obligatorio". El Partido Liberal sustentaba esta adición en el

proyecto afectara el que, según sus miembros, era uno de los mayores logros de la Constitución de 1991: la acción de tutela ("El pulso político", 2010).

17

Véase también González, J. I. (2011). 
hecho de que la Corte Constitucional modula los efectos de sus sentencias cuando lo considera necesario. Este mecanismo, según dicho partido, permitiría que se discutieran los efectos y alcances de los fallos en las finanzas de las entidades a cargo de cumplirlos, con el propósito de modularlos o diferirlos. ${ }^{18}$ El mecanismo en cuestión sería después reglamentado en la Ley 1695 de 2013, la cual ha llevado a que revivan los argumentos aquí expuestos.

\section{La discusión fuera del Congreso}

Fuera del marco del debate estrictamente legislativo, se han discutido también los efectos de la reforma en comento, y los argumentos, de nuevo, cumplen con las condiciones expuestas arriba y se refieren, como se verá a continuación, a los mismos puntos. En este ámbito los argumentos críticos de la reforma han sido más contundentes y han tenido más acogida, pues un importante sector de la academia ha atacado el acto legislativo. Por lo tanto, de alguna manera, se tiene una situación opuesta a la observada en el Congreso.

En el lado de los defensores del Estado social de derecho y los derechos sociales, Rodolfo Arango (2011a), durante el trámite del acto legislativo, ya preveía que, según su concepto, el proyecto

18 En palabras del senador Jesús Ignacio García, el incidente de impacto fiscal permitirá determinar "cuáles pueden ser los alcances del fallo que dicten los jueces constitucionales en las finanzas de los departamentos, de los municipios o de las entidades que tienen que cumplir con esos fallos de constitucionalidad o dictados por los jueces constitucionales y que como consecuencia de ese incidente se difiera en el tiempo o se pueda precisamente determinar por el juez que de manera progresiva se vaya haciendo el cumplimiento de los efectos de la sentencia" (Gaceta del Congreso 491 de 2011, págs. 16-17). en cuestión transformaría "la fórmula política de Estado social de derecho en una de Estado de derecho a secas" y que, además, eliminaría "la protección de los derechos sociales por vía de la tutela". César Rodríguez (2011) criticaba también la reforma al afirmar que el proyecto era innecesario, inconveniente e inconstitucional, pues en su opinión, el Gobierno contaba ya con otros mecanismos "para lograr un manejo responsable y sostenible de las finanzas públicas". Además, Rodríguez era categórico al afirmar que el proyecto en cuestión acababa con la acción de tutela. Rodrigo Uprimny, por su parte, señalaba que la sostenibilidad fiscal como derecho estaba claramente dirigida a limitar la garantía de los derechos sociales, lo cual la hacía inconveniente (“¿Conviene elevar?”, s.f.).

Entre los argumentos más recientes podemos citar de nuevo los de Arango, quien presentó, en enero de 2014, una demanda de inconstitucionalidad contra la Ley 1695 de 2013. ${ }^{19} \mathrm{El}$ académico es, en definitiva, uno de los críticos más entusiastas del incidente de impacto fiscal. En un documento publicado en la página de su campaña al Senado, Arango (2013b) afirma, con base en la demanda y esta vez con mucha más fuerza, ${ }^{20}$ que la ley en cuestión acabó totalmente con el Estado social de derecho y que

19 La demanda fue presentada junto con Luis Germán Ortega, Germán Navas, María del Pilar Arango, Miguel Ángel Espinoza, Diego Alejandro Hernández y Jaime Andrés Nieto. La Corte Constitucional, en sentencia C-870 de 2014 (L. G. Guerrero), accedió solo a una porción de las pretensiones de los demandantes y limitó la aplicación del incidente de impacto fiscal en juicios correspondientes a acciones de tutela.

20 Esta fuerza, posiblemente, podría provenir del hecho de que el profesor Arango se encontraba en campaña política. 
nos llevó a darle la bienvenida al que el jurista llama "Estado fiscal". ${ }^{21}$

Existen incluso economistas que han atacado la reforma. César González (2011) afirma que detrás del proyecto estuvo todo el tiempo "la intención velada de amarrar los derechos sociales y económicos de la población a reglas rígidas de carácter fiscal, sin tocar los impuestos". Incluso Salomón Kalmanovitz (2011), quien ha sido uno de los críticos de la influencia de la jurisprudencia de la Corte Constitucional en las finanzas del Estado, afirmó en su momento que la reforma generaba rigideces innecesarias y contraproducentes para la política económica del país. Anotó que la sostenibilidad fiscal no solo era amenazada por los fallos judiciales que amparan derechos sociales y que generan gastos para el Estado, sino también por otras medidas y circunstancias que no provienen solo de la rama judicial: "exenciones arbitrarias y mal planificadas de los impuestos" o "la corrupción desbordada que abre las venas del presupuesto y deja a la sociedad sin obras ni servicios públicos", entre otras (Kalmanovitz, 2011).

En el lado contrario de la discusión, es decir en el de los defensores de la reforma, encontramos argumentos que, como ocurre en el Congreso, defienden un manejo disciplinado de las finan-

21 Esta no es la primera vez que Rodolfo Arango lanza este tipo de llamados de advertencia. Por ejemplo, desde el momento de la promulgación del acto legislativo, ya preveía la sustitución constitucional del Estado social de derecho por un "Estado fiscal", como consecuencia de las posibilidades que, según el constitucionalista, el incidente de impacto fiscal abre para la limitación de derechos por simples razones económicas (Arango, 2011b). De igual manera, en una columna de 2013, presentó estos mismos argumentos y le dijo adiós a la acción de tutela (Arango, 2013a). zas del Estado y resaltan cómo este llevará en el mediano y en el largo plazo a que se cumplan los postulados del Estado social de derecho. Vale la pena citar a juristas como Mauricio Rosillo (2011), quien felicitó al Gobierno en su momento y considera que el proyecto es un "acto de responsabilidad con las futuras generaciones", que impide que el Estado caiga en la quiebra, y la sociedad en la recesión y el retroceso.

Igualmente, son varios los economistas que han defendido la reforma. Cabe citar a Steiner (2011), quien critica la intervención judicial en la economía y la producción de fallos que implican gastos no previstos por el Ejecutivo. El economista considera "que tiene razón el gobierno cuando señala que la introducción del Principio de Sostenibilidad Fiscal no atenta contra dichos derechos [económicos y sociales], simplemente busca garantizar que los mismos sean sostenibles en el tiempo".

\section{Control de constitucionalidad de la reforma: jurisprudencia de la Corte Constitucional}

Como consecuencia de las múltiples demandas que se presentaron durante el término que la Carta otorga para hacerlo, 22 la Corte Constitucional profirió una sola sentencia con un pronunciamiento de fondo sobre una posible sustitución de la Constitución. Se trata de la sentencia C-288 de 2012 (L. E. Vargas). En esta, el deman-

\footnotetext{
22 En virtud del artículo 379 de la Constitución Política, el término para presentar demandas de inconstitucionalidad en contra del acto legislativo en comento se venció el día 1 de julio de 2012, un año después de su promulgación.
} 
dante alegaba una sustitución de varios pilares de la Constitución, entre los que se encuentran “la primacía de los derechos fundamentales, la independencia del poder judicial, la autonomía de las entidades territoriales y la delimitación de la competencia del Gobierno y el Ministerio Público" (CConst., C-288/2012, L. E. Vargas). En la demanda se afirmaba que el Acto Legislativo 03 de 2011 lleva a que la función del Estado pase de ser la salvaguarda de los derechos fundamentales a convertirse en el mantenimiento de la disciplina fiscal.

La Corte Constitucional declaró exequible el acto legislativo (tal y como ocurrió en las demás sentencias en que lo revisó). Después de hacer una revisión conceptual e histórica de la reforma, la Corte presenta, para fundamentar su decisión, una serie de consideraciones que se sintetizan a continuación:

a. El acto legislativo no implica una modificación de los objetivos esenciales del Estado social de derecho, pues este núcleo dogmático de la Constitución no sufre ningún cambio nominal. Los cambios de este tipo se concentran en disposiciones de la Constitución económica, las cuales se caracterizan por ser normas instrumentales y no fines en sí mismas. Por lo tanto, una modificación de estas normas no altera la base dogmática de la Carta.

b. El criterio de sostenibilidad fiscal, en ese sentido, tiene también un carácter meramente instrumental; de ninguna manera puede considerarse un principio constitucio- nal, así el título del acto legislativo contenga esa palabra. La reforma es clara: la sostenibilidad fiscal es simplemente un instrumento, criterio o marco orientador para contribuir a materializar los fines del Estado social de derecho. No es posible plantear una antinomia o conflicto entre la sostenibilidad fiscal y los principios y fines del Estado social de derecho, pues se encuentran en planos jerárquicos totalmente diferentes.

c. El criterio de sostenibilidad fiscal, según se desprende del acto legislativo, "se interpreta conforme al principio de progresividad y a la naturaleza indivisible e interdependiente de los derechos" (CConst., C-288/2012, L. E. Vargas). En ningún caso esta circunstancia significa un obstáculo para la protección de los derechos constitucionales. La prohibición de "invocar la sostenibilidad fiscal para menoscabar los derechos fundamentales, restringir su alcance o negar su protección efectiva" (cP, art. 334) se debe interpretar de acuerdo con los criterios que la Corte ha establecido en su jurisprudencia más reciente para definir la iusfundamentalidad de un derecho.

d. La reforma contiene claras y específicas cláusulas prohibitivas con respecto a la restricción de los derechos fundamentales y del gasto público social.

e. No existen razones que lleven a concluir que el incidente de impacto fiscal, tal y como lo prevé la reforma, afecte la separación de poderes y la independencia judicial, por las 
siguientes razones: 1) este aparece simplemente como un mecanismo de interlocución entre los poderes del Estado; 2) se limita a promover un debate con respecto a los efectos de una sentencia que pueda afectar la sostenibilidad fiscal, mas no con respecto a la sentencia o decisión como tal, que se encuentra protegida por la cosa juzgada constitucional; 3) la decisión con respecto a la modificación, modulación o diferimiento de los efectos es absolutamente potestativa de la respectiva alta Corte.

\section{EL CRITERIO DE SOSTENIBILIDAD FISCAL: ¿REALMENTE EFICAZ?}

Hasta este punto del texto, es claro que el Acto Legislativo 03 de 2011, como fue promulgado, es una versión bastante moderada del proyecto inicial del Gobierno. Fue prácticamente una constante en el Congreso la preocupación de que la sostenibilidad fiscal, entendida como derecho o como principio, quedara al mismo nivel de un derecho fundamental cuando un juez constitucional los ponderara. Esta inquietud llevó a que finalmente la sostenibilidad fiscal se estableciera como un instrumento, criterio o marco orientador, términos con los que se describe el concepto tanto en el acto legislativo como en la jurisprudencia que lo ha interpretado. En esta última, específicamente en la sentencia que se acaba de sintetizar, se ha resaltado que de ninguna manera la sostenibilidad fiscal puede considerarse un principio constitucional. Además, se ha aclarado que se encuentra en un plano jerárquico inferior al de los fines y postulados del Estado social de derecho, y de los derechos fundamentales. Solo interpretado de esa manera es que el acto legislativo resulta exequible a los ojos de la Corte Constitucional. Esta moderación del proyecto original del Gobierno se convierte en un fuerte límite interno de la figura y, ya desde la manera misma como se concibe en el texto, reduce su eficacia.

Como se dijo anteriormente, durante el trámite legislativo se reconoció que la reforma constitucional está dirigida principalmente contra la intervención judicial en el gasto público. Así lo ha reconocido también la literatura sobre el tema (Rosas, Plazas y Bernal, 2013; Steiner, 2011). No obstante, el mismo acto legislativo establece que la sostenibilidad fiscal debe orientar todas las ramas y órganos del poder público. En este sentido, a continuación se realiza, por medio de un barrido de documentos y entrevistas, una aproximación crítica a los efectos de la reforma constitucional en cada uno de los tres poderes del Estado, para sustentar la tesis que orienta este trabajo.

\section{A. La sostenibilidad fiscal en el Poder Legislativo: discusiones antiguas $e$ intentos de desarrollo del Acto Legislativo 03 de 2011}

Después de la promulgación del Acto Legislativo 03 de 2011, a pesar de que se observan referencias a la sostenibilidad fiscal en las discusiones del Congreso, no existe un cambio estructural en la manera como se incorpora el criterio en los debates y en la legislación. En esta sección, a partir de un estudio de algunos números de 
la Gaceta del Congreso y de leyes posteriores a la reforma, se realiza un acercamiento a los principales casos en los que se ha invocado el criterio de sostenibilidad fiscal en el Legislativo, para sustentar la idea propuesta.

\section{Proyectos relacionados con gasto público social}

Para comenzar, la sostenibilidad fiscal ha tomado lugar en el debate legislativo de algunos proyectos que implican gasto público social ${ }^{23} \mathrm{y}$ que han sido tramitados recientemente, pero como se verá, estas discusiones no son nuevas en el Congreso. A continuación se resaltan dos ejemplos. En primer lugar, la sostenibilidad fiscal aparece reflejada en el Proyecto de Ley Estatutaria de Reforma a la Salud, declarado exequible por la Corte Constitucional en mayo de 2014. En el literal i) del artículo 6 de dicho proyecto se incluye la sostenibilidad entre los "elementos y principios del derecho fundamental a la salud". Al respecto, el proyecto establece que "el Estado dispondrá, por los medios que la ley estime apropiados, los recursos necesarios y suficientes para asegurar progresivamente el goce efectivo del derecho fundamental a la salud, de conformidad con las normas constitucionales de sostenibilidad fiscal" (Proyecto de Ley

23 Como anota Restrepo (2008), el artículo 350 de la Constitución Política contiene la que probablemente es "la más importante innovación en materias presupuestales de la nueva Constitución: la creación de la figura del gasto público social" (pág. 347). Según el artículo 41 del Decreto 111 de 1996, el gasto público social es aquel que tiene como propósito "la solución de las necesidades básicas insatisfechas de salud, educación, saneamiento ambiental, agua potable, vivienda, y las tendientes al bienestar general $y$ al mejoramiento de la calidad de vida de la población, programados tanto en funcionamiento como en inversión" (D. 111/1996, art. 41).
Estatutaria 209 de 2013 Senado y 267 de 2013 Cámara, art. 6. Cursivas añadidas). ${ }^{24}$

En segundo lugar, cabe estudiar las discusiones sobre el Proyecto de Ley 147 de 2013 Cámara y 210 de 2013 Senado, que "redefine el Sistema General de Seguridad Social en Salud" y que fue presentado en marzo de 2013 por el ministro de Salud y Protección Social, Alejandro Gaviria. En este proyecto también se incluye una referencia puntual a la sostenibilidad como principio del Sistema General de Seguridad Social en Salud. Esta circunstancia, aunada a la referencia que se hace en el proyecto de ley estatutaria citado, Ilevó a que se discutiera en el Congreso el peligro de someter la efectividad del derecho a la salud a criterios de sostenibilidad de las finanzas (Gaceta del Congreso n.os 116, 671 y 956 de 2013, entre otras)..$^{25}$

Se podría decir que estos dos proyectos son ejemplos de la eficacia de la sostenibilidad fiscal al interior del Legislador. No obstante, a pesar de existir referencias explícitas a la sostenibilidad fiscal tanto en los textos de estos dos proyectos como en sus respectivas discusiones, estas no tienen el carácter suficiente para afirmar que el Acto Legislativo 03 de 2011 haya producido un cambio radical en la visión del Congreso con respecto a los derechos y al gasto público, en general, y al derecho a la salud,

\footnotetext{
24 Más adelante, al abordar el criterio de sostenibilidad fiscal en el Poder Judicial, se estudiará la decisión de la Corte Constitucional con respecto a la exequibilidad de este aparte.

25 El Proyecto de Ley 147 de 2013 Cámara y 210 de 2013 Senado fue archivado en junio de 2014 por tránsito de legislatura (en virtud del artículo 190 de la Ley $5^{\mathrm{a}}$ de 1992).
} 
en particular. Si se realiza un estudio histórico del texto de la Ley 100 de 1993, se constata que en el artículo 153, que contiene los principios del Sistema de Salud, ya existía uno de sostenibilidad antes de que se promulgara la reforma constitucional objeto de este trabajo. De hecho, para irnos más atrás, el Acto Legislativo 01 de 2005 introdujo en la Constitución la noción de sostenibilidad financiera en el Sistema de Pensiones específicamente. En ese orden de ideas, las discusiones sobre sostenibilidad en el Congreso no son nuevas ni llegan al debate legislativo con la promulgación de la enmienda constitucional que se analiza en esta investigación; la polémica existe en nuestro país desde hace varios años. Por esta razón, no es verdaderamente posible generar un vínculo entre la introducción del criterio de sostenibilidad fiscal en la Constitución y las alusiones a esta noción en proyectos y debates recientes. ${ }^{26}$

26 Rosas et al. (2013) hacen referencia a las leyes 1438 (Reforma a la Salud) y 1448 de 2011 (Ley de Víctimas) como ejemplos de la observancia de la sostenibilidad fiscal en el Legislativo. Sin embargo, estos dos ejemplos no son realmente aplicables, si se tiene en cuenta que las leyes mencionadas fueron promulgadas el 19 de enero y el 10 de junio de 2011, respectivamente, en los dos casos antes del Acto Legislativo 03 de 2011 (que es del 1 de julio). Ante esto, pierde fuerza el argumento. Los trámites de estas dos leyes fueron, máximo, simultáneos con el del Acto Legislativo 03 de 2011 (el proyecto que se convirtió en la Ley 1438 de 2011 fue radicado el mismo día que el del acto legislativo y el proyecto que fue finalmente sancionado como Ley 1448 de 2011 fue presentado en los primeros días del gobierno Santos). Posiblemente, la introducción de la sostenibilidad en los textos de las leyes citadas es un resultado del carácter estructural que, según se ha afirmado en este texto, tiene el debate sobre la sostenibilidad fiscal, sumado a la influencia del Gobierno. En todo caso, estas dos normas solo llevan a darle más apoyo a la tesis de este trabajo, pues incorporan en sus textos alusiones a la sostenibilidad antes de que se promulgara el acto legislativo.

\section{Proyectos directamente referidos al Acto Legislativo 03 de 2011}

La sostenibilidad fiscal también se observa en discusiones y proyectos que se relacionan directamente con el Acto Legislativo 03 de 2011 al desarrollarlo o regularlo, pero que no aplican el criterio de sostenibilidad fiscal como un instrumento o marco orientador en el diseño de políticas públicas. En consecuencia, no se puede hablar de un cambio de paradigma en el Congreso en este sentido. Cabe citar dos ejemplos: la Ley 1695 de 2013, a la que se hizo referencia al principio de este texto, que reglamenta el incidente de impacto fiscal; y un proyecto proveniente del Partido Conservador, que fue archivado en junio tanto de 2012 como de 2013 por tránsito de legislatura, ${ }^{27}$ y que tenía el propósito de desarrollar "el principio de sostenibilidad fiscal como Norma Orgánica Presupuestal" (Gaceta del Congreso n.os 708 de 2011, pág. 25 y 463 de 2012, pág. 25. Cursivas añadidas). Sin embargo, en estos casos, como se dijo, no se invoca la sostenibilidad fiscal para generar un límite en el gasto que implica el diseño o la implementación de determinada política pública. Son simplemente ejemplos de normas que buscan reglamentar o desarrollar la reforma constitucional por la que se introdujo la sostenibilidad fiscal, pero que estrictamente no la aplican.

27 El artículo 190 de la Ley $5^{\mathrm{a}}$ de 1992 establece: "Los proyectos distintos a los referidos a leyes estatutarias que no hubieren completado su trámite en una legislatura y fueren aprobados en primer debate en alguna de las Cámaras, continuarán su curso en la siguiente en el estado en que se encontraren. Ningún proyecto será considerado en más de dos legislaturas" (L. 5/1992, art. 190). 


\section{Conceptos del Gobierno sobre proyectos de ley}

Finalmente, en el trámite legislativo, se observa el concepto de sostenibilidad fiscal en algunos conceptos que entidades del Gobierno como el Departamento Administrativo para la Prosperidad Social, el Ministerio de Salud y Protección Social, y el Ministerio del Trabajo presentan con respecto a determinados proyectos de ley que implican gastos. ${ }^{28}$ Entre muchos otros, podemos citar proyectos como los siguientes, frente a los que las entidades mencionadas han rendido conceptos en los que, independientemente de que sean favorables o no, invocan la sostenibilidad fiscal:

- Proyecto de Ley 90 de 2012 Senado, que buscaba modificar "el régimen de pensión de vejez por alto riesgo para los controladores de tránsito aéreo de la Aeronáutica Civil". ${ }^{29}$

- Proyecto de Ley 120 de 2013 Cámara y 207 de 2014 Senado, que busca crear "la Dirección de Salud Mental y Asuntos Psicosociales para el fortalecimiento de la política de salud mental en Colombia". ${ }^{30}$

- Proyecto de Ley 161 de 2013 Cámara, que busca implementar "mecanismos de apoyo

28 Si bien estos conceptos provienen del Gobierno, se incluyen en esta sección pues hacen parte del trámite legislativo.

29

Véase el concepto del Ministerio del Trabajo en la Gaceta del Congreso 686 de 2013.

30 Véanse los conceptos del Ministerio de Salud y Protección Social en los n. os $^{3} 32$ y 661 de 2014 de la Gaceta del Congreso. para la atención integral a la población en situación de discapacidad". ${ }^{31}$

- Proyecto de Ley 328 de 2013 Cámara y 202 de 2013 Senado, por el cual la Nación se asocia al centenario de fundación de Cajamarca (Tolima). ${ }^{32}$

¿Qué ocurre en estos casos? El Gobierno conceptúa sobre el impacto que los proyectos tienen sobre las finanzas del Estado y para eso invoca la sostenibilidad fiscal. Se podría argumentar, entonces, que por esa vía el Gobierno introduce esta dimensión al debate legislativo. Pero esto tampoco es nuevo. Desde antes de 2011, esta práctica ya era parte de la cotidianidad del Congreso, dado que el Gobierno es, por la naturaleza de sus funciones, el encargado de velar por el manejo adecuado de la política de gasto. Figuras como el Marco Fiscal de Mediano Plazo, ${ }^{33}$ desde antes del Acto Legislativo 03 de 2011 y las medidas fiscales que lo acompañan, obligan al Congreso a contar con el concepto del Gobierno para expedir medidas y políticas públicas que impliquen gasto y, por lo tanto, le abren la puerta a nociones como la sostenibilidad fiscal.

De esta manera, se evidencia que la sostenibilidad fiscal sí se ha contemplado en el Congreso tanto en discusiones como en disposiciones

31 Véase el concepto del Departamento Administrativo para la Prosperidad Social en la Gaceta del Congreso 206 de 2014.

32 Son muchos los proyectos de este estilo que se discuten en el Congreso. Con respecto a este particular, véase el concepto del Departamento Administrativo para la Prosperidad Social en la Gaceta del Congreso 53 de 2014.

33 Véase la Ley 819 de 2003. 
concretas en algunos proyectos. No obstante, las referencias al criterio en estudio no son suficientes para sustentar la idea de un cambio de paradigma que demuestre la eficacia del Acto Legislativo 03 de 2011. Las recientes remisiones a la sostenibilidad fiscal se refieren a discusiones que ya tenían lugar antes de promulgada la reforma o se dan en intentos de desarrollar o reglamentar específicamente el acto legislativo.

\section{B. La sostenibilidad fiscal en el Poder Ejecutivo: una preocupación de vieja data}

Como se indicó antes, la preocupación por la sostenibilidad fiscal en el Ejecutivo no es nueva, pues es prácticamente inherente a sus funciones. Así lo confirman varios expertos desde diferentes perspectivas, quienes además afirman que históricamente Colombia ha sido un país disciplinado en el manejo de las finanzas (M. Eslava, comunicación personal, 10 de noviembre de 2014; M. Pachón, comunicación personal, 6 de noviembre de 2014; R. Steiner, comunicación personal, 7 de noviembre de 2014). Esto lleva a que en su funcionamiento tampoco se observe un verdadero cambio de paradigma después de promulgado el Acto Legislativo 03 de 2011.

Ahora bien, resulta interesante plantear una relación entre, por un lado, el "hueco fiscal" ampliamente cubierto por los medios de comunicación durante el segundo semestre de 2014 y la polémica reforma tributaria aprobada a finales del mismo año (Ley 1739 de 2014); y por el otro, la sostenibilidad fiscal y la regla fiscal. Esta regla va de la mano de la enmienda constitu- cional que aquí se estudia y su objetivo es que, en lugar de que el Gobierno financie nuevos proyectos a partir de deuda, lo haga a través de recursos fiscales. Economistas como Marcela Eslava (comunicación personal, 10 de noviembre de 2014) y Miguel Urrutia (comunicación virtual escrita, 5 de noviembre de 2014) afirman que en este contexto se observa, actualmente, un cambio en las posibilidades que el Gobierno tiene ante la existente diferencia entre ingresos y gastos. Para enfrentar las presiones causadas por estos últimos, el Gobierno, bajo la gobernanza de la regla fiscal, debe acudir a los ingresos en lugar de aumentar el endeudamiento. ${ }^{34}$ Es por esta razón que se propuso la reforma ${ }^{35}$ que finalmente fue promulgada el 23 de diciembre de 2014.

Para recapitular, se observa una modificación interna en el Ejecutivo, referida especialmente a las estrategias que puede aplicar ante las presiones provenientes del gasto. No obstante, este cambio no tiene la entidad necesaria para acabar con los derechos sociales, con la acción de tutela o con el Estado social de derecho, como afirman los opositores del acto legislativo. Al contrario, puede ser un cambio saludable para el Estado. Además, es realmente una consecuencia de la regla fiscal, más que del criterio de sostenibilidad fiscal, que es el instrumento cuya eficacia se analiza en este trabajo. Cabe

Incluso, según Miguel Urrutia (comunicación virtual escrita, 5 de noviembre de 2014), la regla fiscal llega a replantear la relación entre el Gobierno y el Banco de la República "al evitar la tentación del gobierno de endeudarse con el Banco para cubrir un déficit fiscal, lo cual dificultaría lograr los objetivos de controlar la inflación". 
anotar, en todo caso, que es innegable que varios de los gastos que el Gobierno tiene que manejar provienen de los ascendentes compromisos de reconocimiento y garantía de los derechos sociales y económicos. Sin embargo, este texto tampoco apunta a criticar, de ninguna manera, la tendencia a la protección de dichos derechos.

\section{La sostenibilidad fiscal en el Poder Judicial: reiteración de jurisprudencia}

La sentencia C-288 de 2012 (L. E. Vargas), sintetizada anteriormente, insistió en las limitaciones que el criterio de sostenibilidad fiscal tiene frente a los derechos fundamentales y al Estado social de derecho. En este orden de ideas, la jurisprudencia de la Corte Constitucional en la que se toca el tema de la sostenibilidad reitera en gran parte la doctrina contenida en dicha sentencia, lo cual de nuevo lleva a que se reduzcan las opciones de eficacia del Acto Legislativo 03 de 2011, ahora en el Poder Judicial. Sin embargo, existe una sentencia que conviene analizar porque plantea una excepción a la regla general que se acaba de proponer: la SU-1073 de 2012 (J. I. Pretelt). A continuación, se estudian algunos ejemplos de sentencias de la Corte que resultan relevantes.

\section{Sentencias de constitucionalidad en las que se reiteran las consideraciones de la C-288 de 2012}

Son varias las providencias en las que se reitera la posición planteada en la sentencia C-288 de 2012 (L. E. Vargas). En algunas sentencias de constitucionalidad, la Corte estudia normas que incorporan la sostenibilidad fiscal para guiar el proceder de las autoridades. Es cierto que en las sentencias que se citan a continuación la Corte no llega al extremo de declarar inexequibles las normas demandadas por incorporar el criterio. Pero, en todo caso, sí delimita la interpretación de este, de acuerdo con los parámetros de la sentencia mencionada, lo cual claramente termina por reducir su eficacia. A continuación, se hace referencia a algunos ejemplos.

Por un lado, una de las normas cuya exequibilidad se estudia recurrentemente en dichas sentencias es la Ley de Víctimas. Así, en la sentencia C-753 de 2013 (M. González), la Corte estudia una acción de inconstitucionalidad contra esta ley y dos de sus decretos reglamentarios. En las tres normas se incluyen disposiciones que ordenan aplicar criterios de sostenibilidad fiscal en la reparación a las víctimas. La Corte las declara exequibles, pero "reitera que si bien la sostenibilidad fiscal ha sido consagrada en la propia Constitución, no es un criterio que pueda invocarse para limitar o negar los derechos fundamentales de las víctimas o de restringirlos en su esencia" (CConst., C-753/2013, M. González). En este orden de ideas, el tribunal resuelve que las normas demandadas no menoscaban el derecho de las víctimas a la reparación. La Corte estudia otra disposición parecida de la Ley de Víctimas en la sentencia C-581 de 2013 (N. Pinilla) e, igualmente, reitera las consideraciones de la sentencia C-288 de 2012 (L. E. Vargas). Concluye, entonces, que no se puede considerar inconstitucional la norma por obligar a tener en cuenta el criterio de sostenibilidad fiscal en 
las actuaciones realizadas por las autoridades y que tengan efectos sobre las víctimas.

Por otro lado, la Corte hace un análisis parecido en la sentencia C-313 de 2014 (G. E. Mendoza), en la que analiza la exequibilidad del Proyecto de Ley Estatutaria de Salud, al que ya se hizo referencia. En esta providencia, entre otros asuntos, la Sala Plena debió estudiar si es constitucional la inclusión del principio de sostenibilidad que, como se vio anteriormente, se introduce en el literal i) del artículo 6 del proyecto. De nuevo, se reiteran las consideraciones de la sentencia C-288 de 2012 (L. E. Vargas), se insiste en que la sostenibilidad fiscal no es un principio constitucional y se concluye que la salud como derecho fundamental se encuentra protegida contra cualquier afectación. La Corte afirma que los requerimientos de inexequibilidad o exequibilidad condicionada que le habían sido presentados, en los que se alega que el proyecto somete el derecho a la salud a la sostenibilidad fiscal, "suponen una lectura inconstitucional y, consecuentemente censurada y excluible, del criterio" (CConst., C-313/2014, G. E. Mendoza).

\section{Sentencias de tutela en las que se rechazan argumentos de sostenibilidad fiscal}

Resultan interesantes las sentencias de tutela en las que la Corte ha amparado derechos fundamentales tras rechazar argumentos contrarios que invocan la sostenibilidad fiscal, lo cual, evidentemente, limita también la eficacia del criterio. Así, por ejemplo, la sentencia T-443 de 2013 (J. I Pretelt) estudia una tutela presentada por una empresa de servicios públicos contra un fallo ${ }^{36}$ que le ordenó la reubicación de unos postes de energía eléctrica. La Contraloría General de la República interviene como coadyuvante de la accionante y, entre sus argumentos para solicitar que se deje sin efectos la sentencia mencionada, indica que esta "incurre en violación directa de la Constitución, pues vulnera el principio constitucional de sostenibilidad fiscal" (CConst., T-443/2013, J. I. Pretelt. Negrilla y cursiva en el texto original). La Corte expresamente rechaza estos argumentos, insiste en la primacía de los derechos sobre la sostenibilidad fiscal y decide confirmar la decisión que declaraba improcedente la tutela.

Igualmente, en la sentencia T-832A de 2013 (L. E. Vargas), la Corte reitera una vez más los argumentos de la sentencia C-288 de 2012 (L. E. Vargas) y establece que el criterio de sostenibilidad fiscal es útil en los escenarios de planeación y ordenación del gasto público, que solo le corresponden al Ejecutivo y al Legislativo. Con respecto a las altas Cortes, señala:

(i) El criterio de sostenibilidad no resulta aplicable en la decisión de juicios concretos como por ejemplo los contenciosos desarrollados en la jurisdicción ordinaria o en el escenario de revisión de tutela; (ii) el criterio de sostenibilidad solo opera luego de ejecutoriada la sentencia que pone fin al caso concreto sometido a escrutinio de la Alta Corte, esto es, en el trámite del incidente de impacto fiscal. En esta última hipótesis; (iii) no basta la alegación genérica del criterio de sostenibili-

El fallo es el resultado de una acción popular. 
dad fiscal para tenerlo como elemento relevante o admisible en el análisis de la eventual modulación de los efectos del fallo en el trámite incidental, pues es indispensable que el interesado justifique adecuadamente su postura y acredite suficientemente el respeto de las cautelas normativas contenidas en el artículo 334 de la C.P. y en las demás disposiciones de la Carta, sin perjuicio del cumplimiento de los restantes requisitos que debe desarrollar el legislador y la decisión definitiva que tome la autoridad judicial correspondiente (CConst., T-832A/2013, L. E. Vargas).

\section{La sentencia SU-1073 de 2012 y la polémica alrededor suyo}

La sentencia SU-1073 de 2012 marca un quiebre con respecto a la línea jurisprudencial que se ha estudiado hasta este punto. En esta sentencia, la Corte estudia varios casos de negativas judiciales a conceder la indexación de la primera mesada pensional cuando los derechos se habían causado con anterioridad a la Constitución de 1991. En resumen, la Sala Plena determina que el derecho a la indexación de la primera mesada es universal, sin importar la fecha en que se haya causado la pensión. El tribunal, entonces, se refiere a la sostenibilidad fiscal al definir la fecha a partir de la cual se debe calcular el pago retroactivo de dicha indexación y computar, además, el término de prescripción de las mesadas anteriores. Al respecto, la Corte establece que la fecha mencionada equivale a la del momento de certeza del derecho. Dado que, según la Sala, solo a partir de esa senten- cia (la SU-1073 de 2012) se consolida la jurisprudencia sobre el tema y, por lo tanto, se genera un derecho cierto y exigible a la indexación de la primera mesada, dicho momento de certeza está dado por la misma sentencia. Es decir, el pago retroactivo y la prescripción se deben contar desde la fecha de notificación de la sentencia SU-1073 de 2012.

La sostenibilidad fiscal es utilizada como apoyo de este particular razonamiento de la Corte:

Observa la Sala que, en caso de ordenar el pago retroactivo de la indexación desde la fecha en la que se presentó la primera reclamación a la entidad, se pondría en riesgo la estabilidad financiera del Sistema General de Pensiones, desconociendo otro principio constitucional: el de sostenibilidad fiscal consagrado en el artículo 334 de la Constitución Política, que ordena que el mismo debe "orientar a las Ramas y órganos del Poder Público, dentro de sus competencias, en un marco de colaboración armónica" (CConst., SU-1073 de 2012, J. I. Pretelt. Cursiva en el texto original; subrayado añadido).

En este orden de ideas, es claro que la Corte no solo aplica la sostenibilidad fiscal para restringir la efectividad de un derecho cuya existencia es reconocida por la misma corporación, sino que la invoca como un "principio constitucional”. No obstante, hay dos cosas fundamentales para anotar con respecto a esta circunstancia. En primer lugar, interpretaciones de este estilo, como se ha evidenciado, no constituyen una tendencia en la jurisprudencia de la Corte. Este es un caso excepcional que ha producido una 
pequeña línea jurisprudencial aplicada específicamente en la indexación de la primera mesada pensional. ${ }^{37}$ Los mismos magistrados de la Corte, además, han reconocido que la sentencia ha causado un "caos" entre las salas de revisión ${ }^{38}$ a la hora de aplicar el precedente. En segundo lugar, es de suma importancia indicar que la manera como la Corte aplica la sostenibilidad fiscal en esta sentencia no es adecuada. La Sala lo invoca, literalmente, como un principio constitucional, lo cual no solo contradice la intención que el Legislador plasmó en el Acto Legislativo 03 de 2011, sino también su misma jurisprudencia, estudiada anteriormente. ${ }^{39}$ Este punto se retomará en las conclusiones.

\section{Aplicación del incidente de impacto fiscal}

Hasta la fecha, no hay un número significativo de casos en los que se haya aplicado el incidente de impacto fiscal previsto en el Acto Legislativo 03 de 2011 y reglamentado por la Ley 1695 de 2013. Por lo tanto, hasta este momento, tampoco se tienen verdaderas evidencias de la eficacia de esta figura. La primera solicitud de apertura la realizó, en marzo de 2013, la Procuraduría General de la Nación, por solicitud del alcalde de Bogotá, Gustavo Petro ("Consejo de

37 Cabe resaltar la sentencia SU-131 de 2013 (A. Julio).

38 Véase la aclaración de voto de los magistrados María Victoria Calle Correa y Luis Ernesto Vargas Silva a la sentencia T-954 de 2013 (L. I. Vargas).

39 Los magistrados María Victoria Calle Correa y Luis Ernesto Vargas Silva han criticado este punto en más de una ocasión. Véase su aclaración de voto a la sentencia T-954 de 2013 (L. I. Vargas) y el salvamento parcial de voto de la magistrada Calle a la sentencia SU1073 de 2012 (J. I. Pretelt Chaljub).
Estado conocerá primer incidente", 2013). Esta fue presentada ante una condena impuesta por el Consejo de Estado al Distrito Capital en noviembre de 2012, en la que le ordena pagar más de $\$ 227000$ millones a aproximadamente 2000 personas afectadas por un derrumbe del Relleno Sanitario Doña Juana ocurrido en 1997 (CE Contencioso Administrativo, Sección Tercera, 1 nov. 2012, Rad. n. ${ }^{\circ}$ 25000-23-26-0001999-0002-04(AG), E. Gil).

La solicitud fue admitida el 28 de mayo de 2013 y el Consejo de Estado se pronunció sobre esta en providencia de 25 de noviembre de 2014 (CE Plena de lo Contencioso Administrativo, 25 nov. 2014, Rad. n. ${ }^{\circ}$ IJ 25000-23-26-000-199900002-05, E. Gil). En esta, accedió a modular mínimamente la condena: ordenó al Distrito desembolsar el $50 \%$ del monto antes del 31 de diciembre de 2014 y el $50 \%$ restante antes del 31 de enero de 2015. Si bien es cierto que se produce una modulación de los efectos de la sentencia controvertida, en la cual se ordenaba efectuar el pago dentro de los diez días siguientes a su notificación, es claro que no tiene una entidad significativa. En la práctica, dada la duración del proceso, el Distrito logró postergar el pago por un poco más de dos años, pero en términos reales la decisión del Consejo de Estado establece un plazo de un mes entre los dos pagos en los que autorizó desembolsar el monto de la condena.

El otro caso que se registra hasta ahora es el de la sentencia C-101 de 2013 (M. González), donde la Corte Constitucional le ordena a la Procuraduría General de la Nación convocar "un concur- 
so público para la provisión en propiedad de los cargos de Procurador Judicial”. La Procuraduría solicitó la apertura del incidente con respecto a los efectos de esta sentencia, pues afirmó que "ocasiona un impacto en las finanzas públicas, mas [sic] específicamente sobre el presupuesto de la Procuraduría" (CConst., Auto 024/2014, M. González), pues la entidad no tiene los recursos para realizar las erogaciones necesarias. La Corte admitió la solicitud de apertura por medio del Auto 024 de 2014 (M. González), pero finalmente, mediante el Auto 168 de 2014 (M. González), declaró desierto el incidente, pues el procurador no lo sustentó dentro del término de treinta días hábiles posteriores a la notificación del primero.

En resumen, es claro que hasta ahora tampoco en el Poder Judicial el criterio de sostenibilidad fiscal ha producido efectos determinantes. Son varias las sentencias en las que se reiteran los argumentos de la sentencia C-288 de 2012 (L. E. Vargas) que limitan la eficacia de la figura, así como aquellas de revisión en las que se protegen derechos fundamentales tras desconocer argumentos que invocan la sostenibilidad fiscal. El incidente de impacto fiscal, por su parte, tampoco ha producido consecuencias que sobresalgan. Ahora bien, es cierto que la sentencia SU-1073 de 2012 (J. I. Pretelt) marca una diferencia en la aplicación del criterio de sostenibilidad fiscal. Sin embargo, existe una clara inconsistencia de la Corte al aplicar esta figura como principio en esa sentencia y, además, como se pudo constatar en esta sección, los fallos de ese tipo no constituyen una tendencia.

\section{CONCLUSIONES}

Para concluir, cabe hacer una breve recapitulación. Este trabajo nace de un análisis del debate alrededor del Acto Legislativo 03 de 2011 tanto dentro como fuera del Congreso. Se encontró que las dos posiciones de esta discusión se caracterizan, por un lado, por un marcado carácter radical y, por otro, por asumir como un presupuesto, para bien o para mal, la eficacia prácticamente total del acto legislativo y del criterio de sostenibilidad fiscal. De hecho, en la literatura disponible sobre el tema no se encuentran inquietudes sobre la eficacia de la norma. Esta investigación, entonces, pretendió ubicarse entre las dos posiciones descritas y cuestionar ese presupuesto que tienen en común sobre los efectos de la reforma. En ese contexto, el objetivo de este escrito puntual no fue defender ni controvertir el criterio de sostenibilidad fiscal, como se ha hecho en la discusión explicada. Su propósito, más bien, fue aproximarse críticamente a las dos posiciones del debate, a través de un acercamiento a los efectos reales del acto legislativo. El acto legislativo no puede ser descrito como una reforma eficaz, pues no se observa un cambio de paradigma en la toma de decisiones de los tres poderes del Estado. No es posible afirmar que el Estado social de derecho haya Ilegado a su fin ni tampoco que la relación entre las autoridades y la economía haya cambiado radicalmente.

Al margen de este texto, es importante señalar que tanto los fines y pilares del Estado social de derecho, entre los que se encuentran los dere- 
chos sociales y la acción de tutela, como la estabilidad macroeconómica le traen beneficios a un país con una economía emergente como la de Colombia. En este sentido, en lugar de proponer una dicotomía irreconciliable, el debate en nuestro país debería apuntar a encontrar perspectivas que concilien las dos posturas. Igualmente, una de las conclusiones que arroja este trabajo es que el diálogo entre los poderes y órganos del Estado puede contribuir al progreso en la consecución de las metas que plantea la Constitución y que el mismo Estado se propone.

Con estas ideas en mente, vale la pena llamar la atención sobre el carácter de criterio, marco o instrumento que el acto legislativo le dio a la sostenibilidad fiscal. Como se constató en este trabajo, el Congreso, durante los ocho debates que constituyeron el trámite de la reforma, moderó bastante la propuesta que el Gobierno había plasmado en el proyecto original. El tránsito de derecho a principio y de principio a criterio no es gratuito; está motivado por un temor a poner la sostenibilidad fiscal al nivel de los fines del Estado social de derecho. A pesar de esto, en el encabezado de la versión finalmente promulgada del acto legislativo (Gaceta del Congreso n.os 708 de 2011, pág. 25 y 463 de 2012, pág. 25) aparece la palabra principio, aunque en la versión conciliada al final del trámite en el Congreso se leía "por el cual se establece el criterio de la sostenibilidad fiscal" (Gaceta del Congreso n.o 487 de 2011, pág. 55, entre otras. Cursivas añadidas). La Corte Constitucional, por su parte, en la sentencia C-288 de 2012 (L. E. Vargas) insiste en el carácter de criterio de este concepto y aclara que la sostenibilidad fiscal es un mero instrumento, nunca un fin en sí misma, sin importar lo que haya quedado plasmado en el título del acto legislativo que, finalmente, no es incorporado en la Carta.

Pues bien, por más que esta pueda parecer una discusión banal, jurídicamente es muy relevante. En el imaginario de quien no profundiza en las discusiones estudiadas en este texto, en Colombia hoy en día existe el principio de sostenibilidad fiscal, con todas las implicaciones semánticas que esto tiene tanto para operadores jurídicos como no jurídicos. Pareciera que el encabezado del acto legislativo hubiera triunfado sobre su trámite, su contenido y su interpretación judicial. Por lo tanto, una de las cosas que se debe aclarar en este texto con toda la contundencia del caso es que, independientemente de la posición que se tenga en los debates aquí estudiados, en Colombia la sostenibilidad fiscal no es un principio ni mucho menos un derecho constitucional.

Resulta preocupante que incluso dentro del mismo Estado se llegue a aplicar como un principio, después de que esto era lo que pretendía evitar el Legislador. Solo por citar un par de ejemplos, si se estudian varios de los conceptos mencionados anteriormente en los que el Gobierno se pronuncia sobre proyectos que se tramitan en el Congreso, se observa que el Ejecutivo invoca la sostenibilidad fiscal como un principio. De igual manera, incluso la misma Corte Constitucional desconoce su jurisprudencia y llega a referirse en la sentencia SU-1073 de 2012, estudiada arriba, al principio constitucional de la sostenibilidad fiscal. Una de las contribuciones de este 
trabajo, por consiguiente, radica en este punto: aclarar que la sostenibilidad fiscal es un criterio orientador. Es importante que esta aclaración sea tenida en cuenta en todos los ámbitos del debate sobre la materia.

Finalmente, ante la actualidad del tema estudiado, cabe aclarar que las discusiones aquí presentadas no se encuentran completamente decantadas. Posiblemente, ante la coyuntura económica nacional e internacional, la sostenibilidad fiscal se verá enfrentada a diversos escenarios de aplicación y discusión en los años venideros. Igualmente, es posible que nuevas solicitudes de apertura del incidente de impacto fiscal motiven pronunciamientos judiciales que aporten nuevas luces al debate. Por lo tanto, la discusión sobre la sostenibilidad fiscal se encuentra abierta y vigente.

\section{Referencias}

1. Afonso, A. (2004). Fiscal sustainability: The unpleasant European case. Money Macro and Finance (MMF) Research Group Conference 2004, (57).

2. Alonso, J. C., Olivera, M. y Fainboim, I. (1998). La sostenibilidad de la política fiscal en América Latina: el caso de Colombia. Washington, D. C.: Banco Interamericano de Desarrollo.

3. Arango, R. (28 de abril de 2011a). Gasto público y derechos fundamentales. Obtenido de El Espectador: http://www.elespectador.com/impreso/opinion/columna- 265734-gasto-publico-y-derechos-fundamentales

4. Arango, R. (2011b). Sustitución del Estado social de derecho por un Estado fiscal. Zero, XXVII(1), 70-72.

5. Arango, R. (5 de junio de 2013a). Adiós a la tutela. Obtenido de El Espectador: http:// www.elespectador.com/opinion/adios-tutela-columna-426194

6. Arango, R. (5 de diciembre de 2013b). Regulación incidente fiscal: adiós al Estado social y a la tutela. Obtenido de rodolfoarango.com: http://www.rodolfoarango.com/regulacionincidente-fiscal-adios-al-estado-social-y-a-latutela/

7. Congreso de la República de Colombia. (17 de junio de 1992). Ley 5 de 1992. Por la cual se expide el Reglamento del Congreso; el Senado y la Cámara de Representantes. Diario Oficial n. ${ }^{\circ} 40.483$.

8. Congreso de la República de Colombia. (23 de diciembre de 1993). Ley 100 de 1993. Por la cual se crea el sistema de seguridad social integral y se dictan otras disposiciones.

9. Congreso de la República de Colombia. (9 de julio de 2003). Ley 819 de 2003. Por la cual se dictan normas orgánicas en materia de presupuesto, responsabilidad y transparencia fiscal y se dictan otras disposiciones. Diario Oficial n. ${ }^{\circ} 45.243$. 
10. Congreso de la República. (22 de julio de 2005). Acto Legislativo 01 de 2005. Por el cual se adiciona el artículo 48 de la Constitución Política.

11. Congreso de la República de Colombia. (19 de enero de 2011). Ley 1438 de 2011. Por medio de la cual se reforma el Sistema General de Seguridad Social en Salud y se dictan otras disposiciones. Diario Oficial $n .^{\circ}$ 47.957.

12. Congreso de la República de Colombia. (10 de junio de 2011). Ley 1448 de 2011. Por la cual se dictan medidas de atención, asistencia y reparación integral a las víctimas del conflicto armado interno y se dictan otras disposiciones. Diario Oficial n.os 45.98 y 41.148.

13. Congreso de la República de Colombia. (1 de julio de 2011). Acto Legislativo 03 de 2011. Por el cual se establece el principio de la sostenibilidad fiscal. Diario Oficial $n .^{\circ}$ 48.117.

14. Congreso de la República de Colombia. (5 de julio de 2011). Ley 1473 de 2011. Por medio de la cual se establece una regla fiscal y se dictan otras disposiciones. Diario Oficial $n$. $^{\circ}$ 48.121.

15. Congreso de la República de Colombia. (2013). Proyecto de Ley Estatutaria 209 de 2013 Senado y 267 de 2013 Cámara. Por medio de la cual se regula el derecho fundamental a la salud y se dictan otras disposiciones. Diario Oficial n. ${ }^{\circ} 48.096$.
16. Congreso de la República de Colombia. (17 de diciembre de 2013). Ley 1695 de 2013. Por medio de la cual se desarrolla el artículo 334 de la Constitución Política y se dictan otras disposiciones. Diario Oficial $n .^{\circ}$ 49.007.

17. Congreso de la República de Colombia. (23 de diciembre de 2014). Ley 1739 de 2014. Por medio de la cual se modifica el Estatuto Tributario, la Ley 1607 de 2012, se crean mecanismos de lucha contra la evasión y se dictan otras disposiciones. Diario Oficial $n .^{\circ}$ 49.374

18. Consejo de Estado conocerá primer incidente de impacto fiscal, en caso Doña Juana. (31 de mayo de 2013). Obtenido de ambitojuridico.com: http://www.ambitojuridico. com/BancoConocimiento/N/noti-13053102_consejo_de_estado_conocera_primer_incidente_de_impacto_fiscal_e/noti130531-02_consejo_de_estado_conocera_ primer_incidente_de_impacto_fiscal_e.asp

19. Consejo de Estado. Sala de lo Contencioso Administrativo. Sección Tercera. Sentencia de 1 de noviembre de 2012. Rad. n. ${ }^{\circ}$ 25000-23-26-000-1999-0002-04(AG). (C. P.: Enrique Gil Botero).

20. Consejo de Estado. Sala Plena de lo Contencioso Administrativo. Sentencia de 25 de noviembre de 2014. Rad. n. ${ }^{\circ}$ IJ 25000-2326-000-1999-00002-05. (C. P.: Enrique Gil Botero). 
21. Constituyente. (1991). Constitución Política de Colombia.

22. ¿Conviene elevar a rango constitucional el principio de sostenibilidad fiscal? (s.f.). Obtenido de lasillavacía: http://lasillavacia. com/movida/conviene-elevar-rango-constitucional-el-principio-de-sostenibilidad-fiscal-23492

23. Corte Constitucional de Colombia. Sentencia C-265 de 1994 (M. P.: Alejandro Martínez Caballero; junio 2 de 1994).

24. Corte Constitucional de Colombia. Sentencia C-288 de 2012 (M. P.: Luis Ernesto Vargas Silva; abril 18 de 2012).

25. Corte Constitucional de Colombia. Sentencia SU-1073 de 2012 (M. P.: Jorge Ignacio Pretelt Chaljub; diciembre 12 de 2012).

26. Corte Constitucional de Colombia. Sentencia C-101 de 2013 (M. P.: Mauricio González Cuervo; febrero 28 de 2013).

27. Corte Constitucional de Colombia. Sentencia C-581 de 2013 (M. P.: Nilson Pinilla Pinilla; agosto 28 de 2013).

28. Corte Constitucional de Colombia. Sentencia C-753 de 2013 (M. P.: Mauricio González Cuervo; octubre 30 de 2013).

29. Corte Constitucional de Colombia. Sentencia SU-131 de 2013 (M. P.: Alexei Julio Estrada; marzo 13 de 2013).
30. Corte Constitucional de Colombia. Sentencia T-443 de 2013 (M. P.: Jorge Ignacio Pretelt Chaljub; julio 11 de 2013).

31. Corte Constitucional de Colombia. Sentencia T-832A de 2013 (M. P.: Luis Ernesto Vargas Silva: noviembre 14 de 2013).

32. Corte Constitucional de Colombia. Sentencia T-954 de 2013 (M. P.: Luis Ernesto Vargas Silva; diciembre 19 de 2013).

33. Corte Constitucional de Colombia. Auto 024 de 2014 (M. P.: Mauricio González Cuervo; febrero 5 de 2014).

34. Corte Constitucional de Colombia. Auto 168 de 2014 (M. P.: Mauricio González Cuervo; junio 4 de 2014).

35. Corte Constitucional de Colombia. Sentencia C-870 de 2014 (M. P.: Luis Guillermo Guerrero Pérez; noviembre 12 de 2014).

36. Corte Constitucional. Sentencia C-313 de 2014 (M. P. Gabriel Eduardo Mendoza Martelo; mayo 29 de 2014).

37. El Gobierno radicó la propuesta de reforma tributaria. (3 de octubre de 2014). Obtenido de Portafolio: http://www.portafolio.co/economia/reforma-tributaria-impuestos-ministerio-hacienda-2014

38. El pulso político por la sostenibilidad fiscal. (24 de noviembre de 2010). Obtenido de Semana: http://www.semana.com/nacion/ 
articulo/el-pulso-politico-sostenibilidad-fiscal/124998-3

39. Gaceta del Congreso 451 de 2010.

40. Gaceta del Congreso 948 de 2010.

41. Gaceta del Congreso 960 de 2010.

42. Gaceta del Congreso 487 de 2011.

43. Gaceta del Congreso 491 de 2011.

44. Gaceta del Congreso 499 de 2011.

45. Gaceta del Congreso 708 de 2011.

46. Gaceta del Congreso 719 de 2011.

47. Gaceta del Congreso 463 de 2012.

48. Gaceta del Congreso 116 de 2013.

49. Gaceta del Congreso 671 de 2013.

50. Gaceta del Congreso 686 de 2013.

51. Gaceta del Congreso 956 de 2013.

52. Gaceta del Congreso 53 de 2014.

53. Gaceta del Congreso 206 de 2014.

54. Gaceta del Congreso 352 de 2014.

55. Gaceta del Congreso 661 de 2014.

56. González, C. (28 de abril de 2011). Sostenibilidad fiscal: mucho ruido y pocas nueces. Obtenido de CongresoVisible.org: http://con- gresovisible.org/agora/post/sostenibilidadfiscal-mucho-ruido-y-pocas-nueces/1388/

57. González, J. I. (2011). La sostenibilidad fiscal y la regla fiscal: un dúo perverso. Foro, (74-75), 115-121.

58. Kalmanovitz, S. (1 de mayo de 2011). La sostenibilidad fiscal. Obtenido de El Espectador: http://www.elespectador.com/opinion/ sostenibilidad-fiscal-columna-266521

59. Kalmanovitz, S. (1999). Las consecuencias económicas de los fallos de la Corte Constitucional. Economía colombiana y coyuntura política, (276), 124-130.

60. Lewin, J. E. (18 de junio de 2011). Las reformas fiscales: más poder para el gobierno. Obtenido de lasillavacía: http://lasillavacia. com/historia/las-reformas-fiscales-mas-poder-para-el-gobierno-25254

61. Ministerio de Hacienda y Crédito Público. (2002). El manejo responsable de la deuda pública: hacia la sostenibilidad. Bogotá: Alfaomega.

62. Presidente de la República de Colombia. (15 de enero de 1996). Decreto 111 de 1996. Por el cual se compilan la Ley 38 de 1989, la Ley 179 de 1994 y la Ley 225 de 1995 que conforman el Estatuto Orgánico del Presupuesto. Diario Oficial n. ${ }^{\circ} 42.692$.

63. Restrepo, J. C. (2008). Hacienda pública (Octava ed.). Bogotá: Universidad Externado de Colombia. 
64. Rodríguez, C. (2 de mayo de 2011). Otro "articulito", o adiós a la tutela. Obtenido de Dejusticia: http://www.dejusticia.org/ index.php?modo=interna\&tema=cultura juridica_y_educacion\&publicacion $=943$

65. Rosas, G., Plazas, M. A. y Bernal, S. (2013). Sostenibilidad fiscal y regla fiscal: aspectos jurídicos y económicos. Bogotá: Instituto CoIombiano de Derecho Tributario.

66. Rosillo, M. (26 de julio de 2011). Sostenibilidad fiscal: un acto de responsabilidad con las futuras generaciones. Obtenido de ambitojuridico.com: http://www.ambitojuridico. com/BancoConocimiento/N/noti-11072608_sostenibilidad_fiscal_un_acto_de_responsabilidad_con_las_futura/noti-11072608_sostenibilidad_fiscal_un_acto_de_responsabilidad_con_las_futura.asp

67. Steiner, R. (10 de mayo de 2011). Regla fiscal y el principio de sostenibilidad fiscal en Colombia. Obtenido de Foco Económico: http://focoeconomico.org/2011/05/10/ regla-fiscal-y-el-principio-de-sostenibilidadfiscal-en-colombia-2/

68. Título del acto legislativo de sostenibilidad fiscal difiere del texto aprobado por el Con- greso. (6 de julio de 2011). Obtenido de ambitojuridico.com: http://www.ambitojuridico. com/BancoConocimiento/N/noti-11070606_titulo_del_acto_legislativo_de_sostenibilidad_fiscal_difiere_de/noti-110706-06_ titulo_del_acto_legislativo_de_sostenibilidad_fiscal_difiere_de.asp

69. Uprimny, R. (2006). Legitimidad y conveniencia del control constitucional a la economía. En R. Uprimny, C. Rodríguez y M. García, ¿Justicia para todos? Sistema judicial, derechos sociales y democracia en Colombia (págs. 147-200). Bogotá: Grupo Editorial Norma.

70. Uprimny, R. y Rodríguez, C. (2010). Constitución, modelo económico y políticas públicas: una propuesta de integración a propósito del debate sobre el derecho a la educación en Colombia. En P. Arcidiácono, N. Espejo y C. Rodríguez (Coords.), Derechos sociales: justicia, política y economía en América Latina (págs. 237-283). Bogotá: Siglo del Hombre Editores.

71. Zuluaga, O. I., Palacios, H., Alonso, G. y Quintero, G. (2011). La sostenibilidad fiscal, un principio para alcanzar los fines del Estado Social de Derecho. Notas Fiscales, (3). 